\title{
Applying Cognitive Work Analysis to the Design of Rapidly Reconfigurable Interfaces in Complex Networks
}

\author{
D. P. JENKINS*, N. A. STANTON, G. H. WALKER, P. M. SALMON, M. S. \\ YOUNG
}

School of Engineering \& Design, Brunel University, Uxbridge, Middlesex, UB8 3PH, UK

*Contact author: daniel.jenkins@brunel.ac.uk Phone: 01895267108

Fax: 01895265546

\begin{abstract}
The objective of this paper is to illustrate the interconnections between the different phases (or tools) within the Cognitive Work Analysis framework; the benefits of extending an analysis across each of the five phases are highlighted through these interconnections. The paper uses a command and control micro-world example to describe how each of the five phases can be used to describe the constraints within the micro-world domain from a different perspective. Based upon the Social Organisation \& Cooperation Analysis, design requirements are extracted in order to develop role specific customisable interfaces for use within the microworld. The interfaces have been specifically developed to communicate real time reconfiguration of the network through each of the individual interfaces; the reallocations of functions or roles are communicated to the actors through changes to the interface.
\end{abstract}

Keywords: Cognitive Work Analysis; Command and Control; Interface Design; Sociotechnical, Networks

\section{Introduction}

The paper aims to address the common concern in the Human Factors field of how to narrow down the gap between analysis and design. Using Cognitive Work Analysis (CWA) a thorough analysis is conducted for a simplistic yet valid 'sensor to effecter' command and control paradigm. Key requirements and visualisation ideas are extracted through a process of examining the connections between the relevant phases.

CWA was selected as the analysis methodology of choice as it offers a structured framework for considering the development and analysis of complex sociotechnical systems. CWA leads the analyst to start by consider the environment the task takes place within and the effect of the imposed constraints on the system's ability to perform its purpose. Based upon this understanding of the domain constraints the analyst is then prompted to answer the question of what activities are conducted within the domain as well as how this activity is achieved and who can perform it.

CWA starts by considering how the system might reasonably perform (formative modelling), rather than focusing on how the system should perform (normative modelling), or how the system currently performs (descriptive modelling). This 
formative approach leads to an event and time independent description of the system. (Sanderson, 2003; Vicente, 1999)

CWA was originally developed at the Risø National Laboratory in Denmark (Rasmussen, 1986). The framework has been developed and applied for a number of purposes including: system modelling (e.g. Hajdukiewicz, 1998); system design (e.g. Bisantz et al, 2003); training needs analysis (e.g. Naikar \& Sanderson, 1999), training program evaluation and design (e.g. Naikar \& Sanderson, 1999); interface design and evaluation (Vicente, 1999); information requirements specification (e.g. Ahlstrom, 2005); tender evaluation (Naikar \& Sanderson, 2001); team design (Naikar et al, 2003); and error management strategy design (Naikar \& Saunders, 2003). These applications have taken place in a variety of complex safety critical domains including: aviation (e.g., Naikar \& Sanderson, 2001); process control (e.g., Vicente, 1999); nuclear power (e.g., Olsson \& Lee, 1994); naval (e.g., Bisantz et al, 2003); military command and control (e.g., Jenkins et al, In Press); petrochemical (e.g. Jamieson et al); road transport (e.g., Salmon et al, In Press); health care (e.g., Burns et al, 2006); air traffic control (e.g., Ahlstrom, 2005); and manufacturing (e.g., Higgins, 1998).

According to Vicente (1999) CWA can be broken down into 5 defined phases, as shown in Table 1. Each of these phases will be described in the subsequent section.

\section{------- Table 1 About Here -------}

Much of the current literature focuses heavily on the first phase of CWA, work domain analysis (WDA). As Hajdukiewicz \& Vicente (2004) point out WDA does not explicitly deal with any particular worker, automation, event, task, goal or interface, because of this its use in a practical setting is often called into question (Darses 2001). Hajdukiewicz \& Vicente (2004) attempt to resolve this issue by making the relationship between WDA and Task Analysis clearer and more explicit. This paper aims to build upon this idea of making the links between phases explicit extending this approach to each of the five phases described by Vicente (1999). The paper attempts to expose the benefits of the lesser discussed latter three phases of CWA using the fourth phase SOCA to inform the design of rapidly reconfigurable interfaces.

CWA provides a structured method for eliciting requirements for sociotechnical systems design and, by extension, for realising the promises of Network Enabled Capability (NEC); according to JSP 777 (2004) 'NEC is about the coherent integration of sensors, decision-maker, weapons systems and support capabilities to achieve the desired effect'. Social Organisation and Cooperation Analysis (SOCA) leads the analyst to recognise that organisational structures in many systems are generated on line and in real time by multiple, cooperating actors responding to the local context (e.g. Beuscart, 2005). In the words of sociotechnical theory this would be a demonstration of the autonomy granted to groups and the freedom members of a group have to regulate their own internal states and relate themselves to the wider system. SOCA is therefore, expressive of the 'simple organisation/complex job' philosophy. It is not necessarily concerned with planning up front the nature of organisational structures that should be adopted in different situations. It is instead concerned with identifying the set of possibilities for work allocation, distribution, and social 
organisation. SOCA explicitly aims to support flexibility and adaptation in organisations (the sociotechnical principle of 'equifinality'; Bertalanffy, 1950) by developing designs that are tailored to the requirements of the various possibilities (the sociotechnical principle of 'multifunctionality; Cherns, 1987). Ironically, SOCA is one of the more neglected phases of CWA (most emphasis being given to Work Domain Analysis). The aim of this paper is to redress this imbalance and to demonstrate the value of SOCA in relation to simple case study of organisational and interface design.

\section{The Domain}

In order to illustrate the interconnectivity between the phases of CWA a domain was required that contained enough complexity to allow formative behaviour, whilst remaining simple enough to describe and understand. A micro-world paradigm (Jenkins et al, in press) was developed to meet these criteria based upon command and control and NEC. The paradigm was developed to represent a range of command and control domains (both military and non-military). Whilst it is accepted that this model is a simplified account of a sensor to effecter networks found in operational environments, the model does attempt to capture the essential features. Other 'sensor to effecter' network analyses have used similar paradigms with some success (e.g. Dekker, 2003).

The paradigm environment is based in an urban setting of approximately 20 hectares; within the environment there are a number of concealed 'targets' that require the system's attention. There are two types of actors distributed within the environment. The first type of actors are reconnaissance units known as 'sensors'. Sensors have the ability to sweep a geographic area and identify targets that need to be attended to. The second type of actors are effecters who are responsible for attending to identified targets. In this simple paradigm sensors are the only actors that can detect targets and effecters are the only actors who can attend to previously identified targets.

There are a number of ways that information can be transmitted between the sensors and effecters which are dependent upon the way that the system is configured. The system can be set up to enable information to be sent via the commanders with information travelling up the hierarchy and then back down to the units in the field; alternatively information can be sent directly from peer to peer. When sending peer to peer the network can be configured so that a sensor can be linked to an effecter. Alternatively the system can be configured so that the sensor has the ability to select the recipient of the information. The system is significantly reconfigurable; the exact configuration choice will be influenced by a number of variables. These include:

- Number of units - how many sensors

- Ratio of effecters to sensors - how many effecters per sensor

- Ratio of targets to sensors - how many targets per sensor

- Complexity of task - are there a number of conflicting requirements

- Complexity of the target - is interpretation of the target required

- Ambiguity of information - is it clear what the information represents 
- Type of information transmitted (e.g., data, voice)

\subsection{Work Domain Analysis}

The first phase of CWA; Work Domain Analysis (WDA) is used to describe the domain in which the activity takes place independent of any goals or activities. Hajdukiewicz \& Vicente (2004) are keen ton point out that WDA does not explicitly deal with any particular worker, automation, event, task, goal, or interface. Via a hierarchy WDA captures the relationships between the physical objects and the system's overall purpose.

The first stage of this process is to construct an abstraction hierarchy ( $\mathrm{AH}$ ) of the domain (see Figure 1). The AH represents the system domain at a number of levels; at the highest level the AH captures the system's raison d'être; at the lowest level the AH captures the physical objects within the system. In this simple sensor-effecter paradigm the sole reason that the system exists is to detect and attend to targets within a predefined area. The system is evaluated against its ability to enact its purpose. This can be measured by a number of criteria, including: the time it takes the effecter to receive a target, how quickly all of the targets can be attended to (this could be achieved by attending to them based on the target's geographical position), the speed at which threat is reduced (this could be achieved by attending to the most dangerous targets first), and the number of errors made. In many circumstances these criteria may be conflicting. An example of this conflict includes units approaching targets in threat priority order; if the same effecter prioritised the targets by their geographical position the targets would be approached in a different order; whilst the route would be shorter and therefore faster to complete, the target with the greatest threat may be the last to be attended to. It could also be argued that the speed to complete and error rates are conflicting constraints, the assumption being that more careful time consuming planning reduces errors.

The bottom level of the AH shows each of the physical objects within the domain; in this case the nodes comprise all of the equipment within the domain. The level above this describes the functions that each of the objects can afford independent of the overall system purpose; in many cases an object may perform a number of functions, in the same way a particular function may be afforded by a number of objects.

The purpose related functions in the middle of the $\mathrm{AH}$ are the functions required to perform the purposes of the system. Each of these levels can be linked by means-ends relationships using the why-what-how relationship. Any node in the AH can be taken to answer that question of 'what' it does. The node is then linked to all of the nodes in the level directly above to answer the question 'why' it is needed. It is then linked to all of the nodes in the level directly below that answer the question 'how' this can be achieved. Taking the example of the 'Capture Location' node in the physical function level, the question of 'what' is clearly answered. The node is then linked to nodes in the level directly above to answer the question of 'why' capture location, (in this case to calculate target position, and prioritise target). The node is then linked below to answer 
the question, 'how' can the location be captured, (in this case by GPS devices and by sensors).

\section{Figure 1 About Here}

The AH can then be decomposed based on levels of resolution through the system. In this case the system was decomposed using the following three categories of resolution: system, subsystem and individual components. Once decomposed, the data can be plotted on the Abstraction-Decomposition Space (ADS). In many cases the nodes are decomposed along the diagonal of the ADS moving across the decomposition axis as they move down the abstraction axis (see Figure 2), according to Hajdukiewicz \& Vicente (2004) at higher levels of abstraction, participants tend to think of the work domain at a coarse level of resolution, whereas at lower levels of abstraction, participants tend to think of the work domain at a detailed level of resolution. The functional purpose(s) of the system in most cases will apply to the total system; likewise the individual physical forms are likely to be either components or subcomponents.

\section{------- Figure 2 About Here -------}

The application of WDA leads the analysts to focus on the reason the system exists considering each of the physical components against their ability to support this. The means-ends links within the abstraction hierarchy capture the flexibility of the system illustrating that the system can often be configured in a number of ways to achieve the same end state. This formative event independent understanding of the constraints within the system forms a basis for further examination of the work domain.

\subsection{Control Task Analysis}

The Work Domain Analysis phase looked at the domain independent of activity. In order to understand the domain further it is advantageous to look at the known recurring activities that occur within this domain. The second phase of the analysis, Control Task Analysis (ConTA), models one or more of these known recurring tasks, focussing on what has to be achieved independent of how the task is conducted or who undertakes it.

Control task analysis uses Rasmussen's (1986) Decision Ladder; the ladder in Figure 3 can be seen to contain two different types of node, the rectangular boxes represent dataprocessing activities and the circles represent states of knowledge resulting from data processing. The decision ladder shows a linear sequence of information processing steps that is folded over. Novice task performers are expected to follow the decision ladder in a linear fashion whereas expert users are expected to by-pass sections of the ladder based on their previous experience and understanding of the system (see links between legs in Figure 3). Individual tasks can be modelled onto the decision ladder Figure 3 illustrates the task of identifying a target and attending to it. The system is activated when a target is spotted (shown on the bottom left leg). Once a target is spotted information is recorded on its location and type (no inference or calculation is 
made). Assessment is then made to calculate the threat of the target. Once a threat has been assigned, the target is then considered relative to the task and the environment and a priority is placed upon it. This prioritisation allows the target to be assigned to an effecter. A target is then identified and finally attended to

Figure 3 About Here

In order to expedite this process it is possible to bypass some of the steps. Removing some of the decision making processes allows the transition from spotting the target to attending to it to be expedited. Figure 3 shows each of the possible leaps (circle to circle) and shunts (circle to square). Figure 3 illustrates that the shortest path for this paradigm is that the target is spotted, information recorded and this information is used to attend to the target.

Naikar et al (2005) describe the contextual activity template for use in this phase of the CWA (see Figure 4). This template is one way of representing activity in work systems that are characterised by both work situations and work functions. According to Naikar et al (2005) the work situations (situations decomposed by schedules or location) are shown along the horizontal axis and the work functions (activities characterised by its content independent of its temporal or special characteristics (Rasmussen et al, 1994)) are shown along the vertical axis of the contextual activity template. The dashed boxes indicate in which situations the work functions can occur, whereas the circles and whiskers indicate where the work functions typically occur.

The work functions captured in this diagram are typically similar to the purpose related functions in the WDA (see Figure 1). For the command and control micro-world three distinctly different situations have been selected due to the constraints enforced by their geographical variation, these are; in the field searching for targets; in the command centre; and in the field attending to targets. Figure 4 shows that the constraints imposed on the system mean that two of the functions are bound by the situations (records information on the type and location; and attend to the target). The functions of prioritising the targets and of assigning the threat can take place in any situation. Figure 4 illustrates that the function of 'calculating the threat of the targets' can occur in any situation however it typically occurs in the field whilst searching for targets. The work function 'record information on the type and location of the target' shown in Figure 4 is constrained to only being able to occur in the field whilst searching for targets. This template is a neat way of graphically illustrating the constraint of the system.

\section{------- Figure 4 About Here -------}

The decision ladder introduced in Figure 3 can be used to communicate which stage of the task is being completed at any particular combination of work situation and function. The diagram on the right shows the contextual activity template overlaid with this information, it should be noted that these decision ladders are only intended to be indicative of the typical area of the decision ladder involved. It is important to point out that this could be completed in a number of ways. 
The application of the ConTA leads the analyst to consider for the first time known reoccurring activity within the domain. Here these typical activities are considered against specific situations and further system constraints are discovered. In this example the acknowledgement that certain activities are bound by geographical location is fundamental to allocation of work.

\subsection{Strategies Analysis}

Strategies analysis is used to look in more detail at known recurring activities. This step of the analysis considers the tasks analysed in the ConTA phase and considers the strategies that may be used to complete them. The strategy adopted by an actor at a particular time may vary significantly. Different actors may perform tasks in different ways; with the same actor also perform the same task in a variety of different ways. There are a number of strategies for achieving the same ends with the system described in the Abstraction Hierarchy. Each of these strategies uses different resources and distributes the workload in different ways. Figure 5 shows six of the most common methods for attending to a target. The list is not intended to be exhaustive; it is intended to capture those methods that are common and most likely.

\section{------- Figure 5 About Here -------}

The analysis plots a strategy moving from a start state of an identified target, to an end state of the target being attended to. Use of the decision ladder representation in Figure 5 illustrates a typical path through the process as a result of selecting a certain strategy. The first strategy shows that the task is completed at a simplistic level by peer to peer communication and without threat calculation or prioritisation. This situation requires the targets to be attended to as they are detected. An example of a more complex situation is situation 6 , here the target is processed centrally and considered with all other targets, a priority is assigned and the appropriate effecter selected.

The strategies analysis phase of CWA leads the analyst to introduce specific strategies for the first time, based upon the information gathered from the previous phases it is possible to quickly populate these representations.

\subsection{Social Organisation \& Cooperation Analysis}

Social Organisation \& Cooperation Analysis (SOCA) models the constraints governing the division of tasks between the resources and addresses how the team communicates and cooperates. The objective is to determine how the social and technical factors in a system can work together in a way that enhances the performance of the system as a whole. It is possible to map each of the identified actor types (sensor, effecter, and commander) on to the existing tools (ADS, Decision Ladder, and Strategies Analysis) in order to show who has the capability of doing what using arbitrary shading (dark, medium, and light grey for the sensor, effecter, and commander respectively) to show where each of the actor groups can conduct tasks. The application of colour coding results in a concise graphical representation, further more verbose annotation is often 
required to capture the reasoning behind the coding as well as to capture the links between the phases.

Figure 6 shows the abstraction-decomposition space (ADS) shaded to show the nodes that can be used by the key actor groups. The total system requirements have been left blank as these are generic and apply to all actors. The diagram clearly shows which of the nodes are specific to individual actors and which of the nodes can be attributed to any actor.

\section{------- Figure 6 About Here -------}

Figure 7 shows the decision ladder introduced in Figure 3 shaded to show where each of the actor types can conduct tasks. Due to the limitations of the system, sensors are the only actors that can detect targets and effecters are the only actors who can attend to previously identified targets (highlighted in Figure 4). This leads to the 'feet' of the ladder being shaded dark for the sensors and 'medium grey' for the effecters. In these cases they are the only actors physically capable of conducting these tasks. The remaining part of the decision ladder involves taking the basic information from the sensor, interpreting it and making a decision about which targets to attend to. In this case this activity can be conducted by the sensor, the commander or the effecter. For this reason the nodes are tri-shaded.

\section{------- Figure 7 About Here -------}

Figure 8 shows that the strategies analysis diagram introduced in Figure 5 can also be shaded to show the actors engaging in the task. Here the initial state must start with the sensor and end with the effecter, however the strategy used in the middle can be enacted by the sensor, the commander or the effecter.

\section{------- Figure 8 About Here -------}

The SOCA phase captures the constraints enforced by the actor type, each of the three representations from the previous sections illustrates these constraints in a different way. The benefit of this phase lies in the ability to capture an understanding of the constraints surrounding task allocation and the allocation of resources. Experimentation is required to decide how the workload should be distributed. The dependent variables listed at the start of this document and the network configuration will affect this decision.

\subsection{Worker Competencies Analysis}

The final phase of the CWA framework, worker competencies analysis (WCA), involves identifying the competencies that actors require for performing the required activity within the system under analysis. WCA is concerned with making the task easier for the end user by use of techniques such as mental models. This section addresses the traditional core concerns of the human factors and HCI communities. 
The Worker competencies analysis phase of CWA can be described by Skills Rules and Knowledge (SRK) based behaviour. According to Rasmussen et al (1994) Skill Based Behaviour (SBB) is performed without conscious attention. SBB typically consists of anticipated actions and involves direct coupling with the environment. Rule Based Behaviour (RBB) is based on a set of stored rules that can be learned from experience or from protocol. During RBB individual goals are not considered, the user is merely reacting to an anticipated event using familiar perceptual cues, unlike SBB, users can verbalise their thoughts as the process is conscious. When decisions are made that explicitly consider the purpose or goal of the system the behaviour can be considered to be Knowledge Based Behaviour (KBB). KBB is slow, serial and effortful because it requires conscious, focal attention.

The optimum network structure will also be dependent on the behaviour level expected from the actors. The behaviour the actors exhibit can be classified into three SRK levels dependent on the level of processing required to complete the desired activity. Figure 9 shows example responsibilities for each of the stages of the process at the three behavioural levels. The design of an interface should allow actors to perform at any of the three levels, however by restricting the information shown on a display the actors can be encouraged to more rigorously follow protocol acting at a rule based level. More knowledge based behaviour can be encouraged by providing the actor with additional contextual information promoting the actor to develop a deeper understanding of the current state of the work domain.

Figure 9 About Here

\section{Sensor to Effecter System Design}

Each of the actors within the command and control micro-world are equipped with either a computer or a PDA. Unsurprisingly the design of the interface for these displays has a significant effect on the efficiency and the efficacy of the actors within the system. The design of the individual displays in the array is informed by the requirements placed on the actor; only the information that is pertinent to the activity is displayed. As the roles change information is added and removed, cues to inform actors that roles and responsibilities had changed were also required from the interface.

Figure 10 shows how the phases of CWA are interconnected in this case; this high level of interconnectivity is one of the strengths of the CWA framework. The domain is first analysed independent of activity in the WDA, here the constraints bound by the functions the physical objects can perform is captured. Known reoccurring tasks can be extracted from the products of the WDA and analysed in greater detail in the ConTA, the ConTA considers how the constraints imposed by the geographical location of the activity affects what functions are possible. The activities identified in ConTA are explored in detail in the strategies analysis (StrA). All three of these phases then feed into the SOCA phase where they are coded to indicate which of the actors can be associated with parts of the process. 
------ Figure 10 About Here -------

The decisions ladder from the SOCA phase (see Figure 7) led the development of the interfaces by capturing the information requirements for the actors, indicating the contextual constraints associated with certain parts of the decision making process, thus the required information can be identified for each of actor groups for any given network configuration. The decision ladder breaks down the activity into a number of processes that can be represented in the interface (see Table 2); the interfaces are constructed to show the minimum information on their base display, this can then be supplemented with additional information as it is needed depended on the activity required from the actor. Table 2 shows that the level of complexity of the display is related to the task being completed with the tasks of identifying and neutralising requiring minimal information and the more considered tasks of selecting prioritising targets and selecting effecters requiring richer information.

Table 2 About Here

In order to visualise the effects of system manipulations a dynamic tool was developed showing the interfaces for each of the three key actors (Figure 11); one for the sensors (bottom left), one for the effecters (bottom right), and one for the commander(s) (top right). The displays are manipulated by assigning different parts of the decision ladder (shown on the top left of the array) to different actors. The decision ladder can be either assigned to sensor, effecter, commander, or not assigned (the part of the task is not required). Figure 11 shows the simplest configuration. In this situation the command is not used in the system, the sensor (shown as the darker ringed circle) has identified a single target (lighter circle) and sent it to the effecter who incidentally happens to be collocated.

Figure 11 About Here

When the sensor is assigned more responsibility the decision ladder is shaded to reflect this change in the system. The interface for the sensor is automatically altered in line indicating to the user that their role has changed. In Figure 12 the sensor is assigned the additional responsibility for assigning the target's threat and priority. In order to complete this task the sensor needs to be provided with the location and details of other targets in order to place a relative priority. In Figure 13 the sensor is required to allocate targets to effecter; to enable them to do this they need to know the location and workload of the effecters. Figure 14 shows the effecter taking responsibility for assigning threat priority, targets and selecting targets. The effecter's display has changed to reflect these responsibilities. The introduction of the commander is modelled in Figure 15. In this case the commander has taken on responsibility for prioritisation and allocation of the targets. 


\section{------- Figure 12 About Here ------- \\ Figure 13 About Here \\ Figure 14 About Here}

A number of further system configurations out of the total of 256 are likely within this paradigm. The system configuration selected will be dependent on a number of factors including:

- Number of units: - larger systems are likely to become more complex, there may be a point where the system starts to perform better with some kind of centralised 'deconfliction'.

- Ratio of effecters to sensors: - the ratio is likely to influence the way the workload is divided between the two types of actor with one group taking over tasks from another to reduce bottlenecks.

- Ratio of targets to sensors: - the number of targets per sensor is likely to be a trigger for a network change in some networks. At a point where the targets become too numerous it may be advantageous for the system to revert to a centralised assignment of targets to sensors.

- Complexity of task: - if there are a number of conflicting requirements the system may benefit from a higher more formative decision making process. This decision making process may not be required if the complexity of the task changes, then a quicker rule based system could be adopted.

It is possible that much of the reconfiguration could be automated based on the development of optimised system formulas. In this case a computer could detect trigger points for system changes and automatically disseminate this change to the actors by reconfiguring their interfaces.

\section{Conclusions}

This paper has described the sensor to effecter system at each of the five CWA phases. The analysis has described the domain and answered questions on why the system exists, what it should do, how it should do it and who should be enacting the various stages of the task. The first phase WDA identified the purpose of the system along with the metrics to asses its performance. The analysis also captured the constraints governing how the system could be utilised in the future when faced with unknown unanticipated events. The second phase ConTA captured the standard recurring task of 
detecting and attending to targets as well as the constraints enforced by the situation within the domain. In the third phase the multitude of strategies for completing this recurring task were examined. The fourth phases introduced assigning the stages of the task to actor groups; here a constraint based approach was used capturing all of the possible organisational combinations to complete the task. Finally the fifth phase WCA identified examples of the behaviour exerted at each of the three levels identified by Rasmussen et al (1994).

The analysis directly informed the design and development of a number of interfaces tailored to each of the actors. The concept of using the decision ladder to map activity of more than one actor (both human and non-human) forms the basis of this display, it is encouraging to see that other authors (Cummings \& Guerlain, in review) have also arrived a similar conclusion. This methodical analytic approach to the design and development of the displays creates a clear 'audit trial' of the design decisions made. This in part removes some of the 'black art' traditionally surrounding interface design.

The CWA by focusing on constraints demonstrates the flexibility of the network: Due to the physical nature of the sensors, they are essential to the system as they are the only method for capturing target positions. The effecters are also essential to the system as they are the only means of attending to targets. The commander/command team has no unique role and is therefore non-essential to the system. The physical actions of sensing and attending to are fixed; however the more complicated tasks of interpreting, evaluating and defining the task can be assigned to anyone within the system, although as the contextual activity template in Figure 4 shows, the situation within the domain is likely to have an effect on the allocation of task.

By changing the roles and responsibilities of the groups of actors, it is possible to compensate for environmental changes by rapidly reconfigure the network. By focusing on the constraints the analysis captures every physically possible network configuration. The potential benefits of rapidly reconfigurable interfaces either automated or manual are great both in terms of system efficiency and speed of task completion.

By focusing more heavily on the fourth phase (SOCA), this paper provides further validation for CWA as a comprehensive framework of tools. As described earlier, the majority of previous CWA applications have utilised only the WDA phase. We contend that future CWA analyses should utilise the phase that is most applicable to both the research aims and the domain in question. Although the SOCA phase has led the design in this case, this phase would not have been completed without the information captured in the preceding phases. This analysis therefore demonstrates the interconnection between the CWA phases and reinforces the benefits of extending a CWA analysis beyond the initial Work Domain Analysis and Control Task Analysis. Further, this paper provides evidence of how CWA, when applied in its entirety as a suite of tools, can be effective in informing the design of systems and interfaces. The framework is often criticised for not providing sufficient guidance to analysts wishing to design novel systems. One reason for this could be that analysts are either using inappropriate CWA phases or that they are not fully completing the analysis. This analysis demonstrates that, when CWA is undertaken appropriately (i.e. the relevant 
phases are utilised), clearly defined traceable design requirements can be more easily extracted from CWA analysis outputs.

Other examples exist within the current literatures with similar aims to this paper; the most notable example is Cummings \& Guerlain's (2004) dual screen interface called the Tactical Tomahawk Interface for Monitoring and Retargeting (TTIMR). The approach used by the authors to develop their interface was based upon an adaptation of CWA; the authors deviate from the 'established' approach proposed by Rasmussen et al (1994) and Vicente (1999) by studying the actors and their social interaction and using this to inform the development of the Work Domain Analysis (described in an earlier text Cummings \& Guerlain's (2003)). This is a novel way of establishing system constraints however care is required in the interpretation of this approach, it is a fundamental and agreed requirement that work domain analysis remains independent of actors and goals (Hajdukiewicz \& Vicente, 2004; Naikar, 2005; Rasmussen, 1994; Vicente, 1999). The aim of this paper has been to use a paradigm to take a more theoretical approach to test the framework with little deviation from the method as it is described by Vicente (1999). This allows CWA in its current guise to be evaluated against its support for the development of design interfaces.

\section{Acknowledgements}

Thanks to Neelam Naikar from the Defence Science and Technology Organisation for her review of a draft of this paper and for her valuable feedback.

This research from the Human Factors Integration Defence Technology Centre was part-funded by the Human Sciences Domain of the UK Ministry of Defence Scientific Research Programme.

Any views expressed are those of the author(s) and do not necessarily represent those of MOD or any other UK government department. 
Table 1 - the phases of CWA (Vicente 1999) (Acquisition methods have been added from Lintern et al (2004))

\begin{tabular}{lll}
\hline Phase & Acquisition & Tool \\
\hline $\begin{array}{l}\text { Work Domain Analysis } \\
\text { (WDA) }\end{array}$ & $\begin{array}{l}\text { Document Analysis } \\
\text { Review by SME }\end{array}$ & $\begin{array}{l}\text { Abstraction } \\
\text { Decomposition Space }\end{array}$ \\
\hline $\begin{array}{l}\text { Control Task Analysis } \\
\text { (ConTA) }\end{array}$ & $\begin{array}{l}\text { Cognitive walk through } \\
\text { Study of Work Practices }\end{array}$ & Decision Ladder \\
\hline Strategies Analysis & $\begin{array}{ll}\text { Critical Decision Method } \\
\text { Interaction Analysis }\end{array}$ & Information flow map \\
& Verbal Protocol Analysis & \\
& & \\
\hline $\begin{array}{l}\text { Social Organisation \& } \\
\text { Cooperation Analysis } \\
\text { (SOCA) }\end{array}$ & $\begin{array}{l}\text { Communication Analysis } \\
\text { Interaction Analysis }\end{array}$ & All of the Above \\
& & \\
\hline $\begin{array}{l}\text { Worker Competencies } \\
\text { Analysis (WCA) }\end{array}$ & $\begin{array}{l}\text { Repertory Grid Analysis } \\
\text { Review of Decision }\end{array}$ & Skills Rules Knowledge \\
& Ladder & \\
\hline
\end{tabular}


Table 2 - Required display information by activity

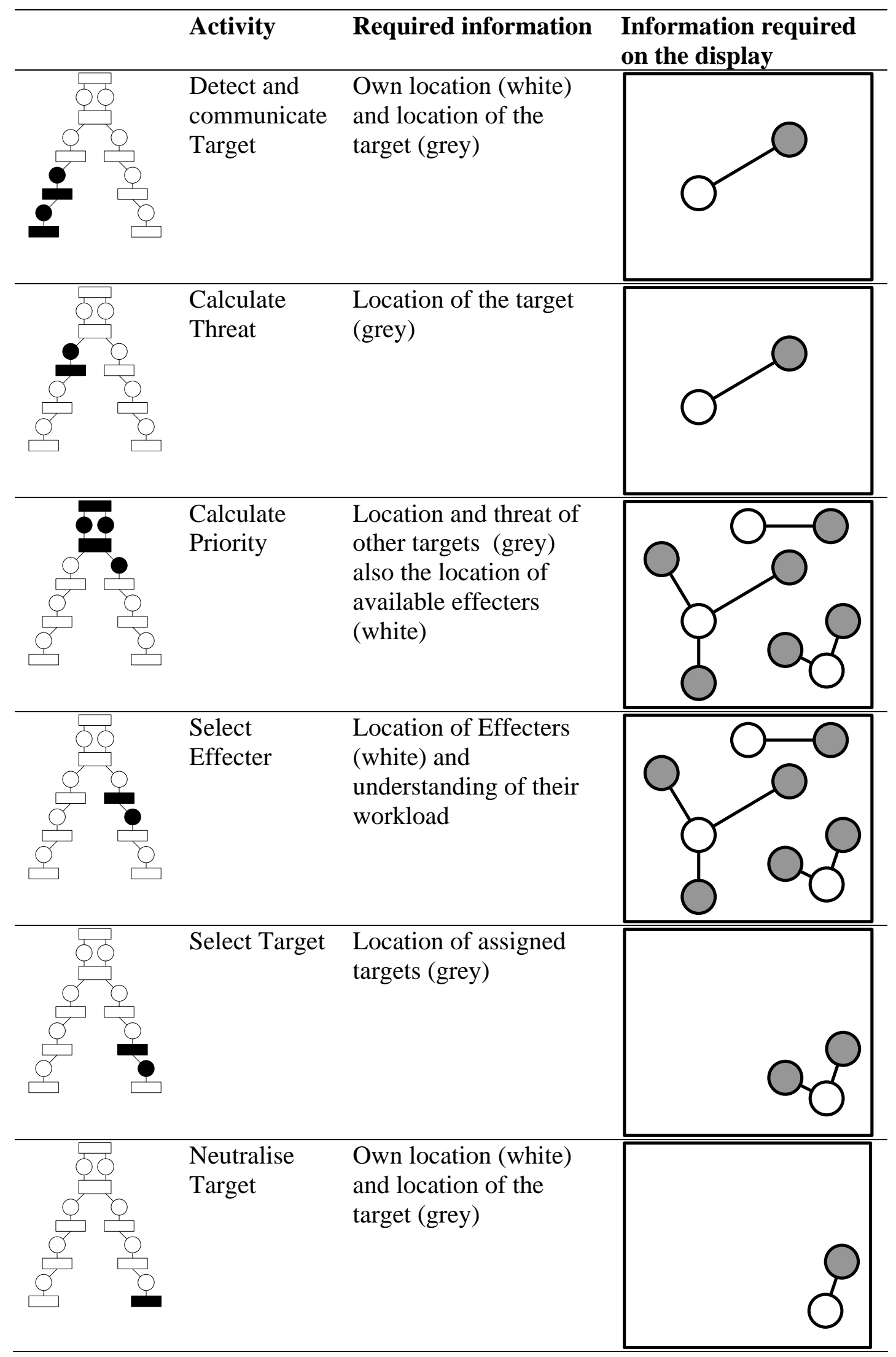




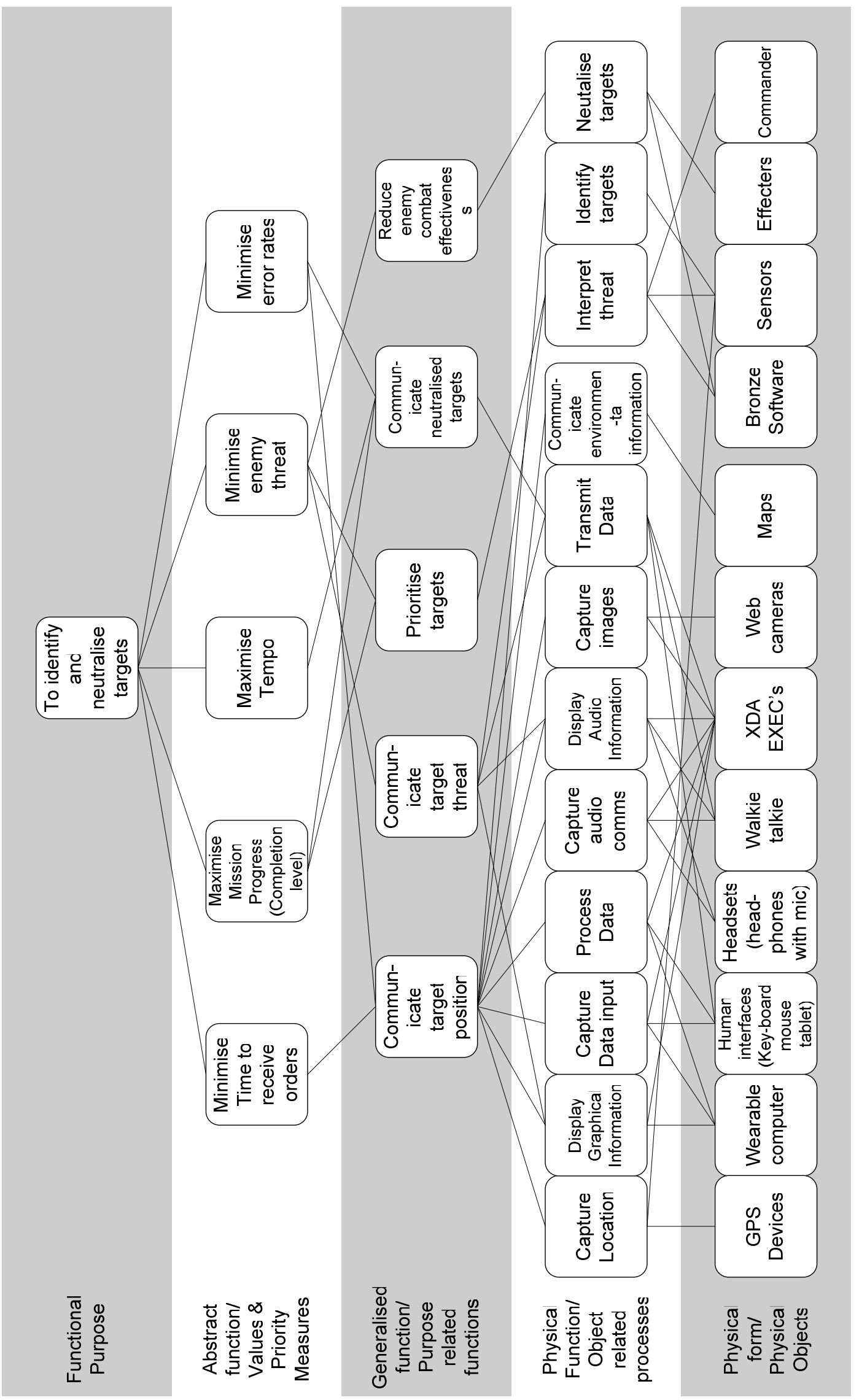

Figure 1 - Abstraction Hierarchy for Sensor-Effecter activity 


\begin{tabular}{|c|c|c|c|c|c|c|c|c|c|c|c|c|c|}
\hline Decomposition & \multicolumn{3}{|c|}{ Total System } & \multicolumn{4}{|c|}{ Sub-System } & \multicolumn{6}{|c|}{ Component } \\
\hline $\begin{array}{l}\text { Functional } \\
\text { Purpose }\end{array}$ & \multicolumn{3}{|c|}{$\begin{array}{c}\text { To identify and neutralise } \\
\text { targets }\end{array}$} & & & & & & & & & & \\
\hline \multirow{2}{*}{$\begin{array}{l}\text { Abstract } \\
\text { function/ } \\
\text { Values \& } \\
\text { Priority } \\
\text { Measures }\end{array}$} & $\begin{array}{l}\text { Minimise } \\
\text { Time to } \\
\text { receive } \\
\text { orders }\end{array}$ & $\begin{array}{l}\text { Maximise } \\
\text { Mission } \\
\text { Progress }\end{array}$ & $\begin{array}{l}\text { Maximise } \\
\text { Tempo }\end{array}$ & & & & & & & & & & \\
\hline & $\begin{array}{c}\text { Minimise } \\
\text { enemy threat }\end{array}$ & $\begin{array}{l}\text { Minimise } \\
\text { error rates }\end{array}$ & & & & & & & & & & & \\
\hline \multirow{2}{*}{$\begin{array}{l}\text { Generalised } \\
\text { function/ } \\
\text { Purpose } \\
\text { related } \\
\text { functions }\end{array}$} & & & & $\begin{array}{l}\text { Communicate } \\
\text { target position }\end{array}$ & \multicolumn{2}{|c|}{\begin{tabular}{|c|c|} 
& Communicate \\
$\mathrm{n}$ & target threat \\
\end{tabular}} & $\begin{array}{l}\text { Prioritise } \\
\text { targets }\end{array}$ & \multirow{3}{*}{\multicolumn{3}{|c|}{$\begin{array}{c}\text { Capture } \\
\text { Location }\end{array}\left(\begin{array}{c}\text { Display } \\
\text { Graphical } \\
\text { Info }\end{array}\right)$}} & \multirow{3}{*}{\multicolumn{2}{|c|}{$\begin{array}{c}\text { Capture } \\
\text { Data input }\end{array}$}} & \multirow[b]{3}{*}{$\begin{array}{l}\text { Capture } \\
\text { audio } \\
\text { comms }\end{array}$} \\
\hline & & & & $\begin{array}{c}\text { Communicate } \\
\text { neutralised } \\
\text { targets }\end{array}$ & \multicolumn{2}{|c|}{$\begin{array}{c}\text { Reduce } \\
\text { enemy } \\
\text { combat } \\
\text { effectiveness }\end{array}$} & & & & & & & \\
\hline \multirow{2}{*}{$\begin{array}{c}\text { Physical } \\
\text { Function/ } \\
\text { Object related } \\
\text { Processes }\end{array}$} & & & & Process Data & \multicolumn{2}{|c|}{ Transmit Data } & $\begin{array}{l}\text { Interpret } \\
\text { threat }\end{array}$ & & & & & & \\
\hline & & & & $\begin{array}{l}\text { Identify } \\
\text { targets }\end{array}$ & \multicolumn{2}{|c|}{$\begin{array}{l}\text { Neutalise } \\
\text { targets }\end{array}$} & & $\begin{array}{l}\text { Display } \\
\text { Audio Info }\end{array}$ & \multicolumn{2}{|c|}{$\begin{array}{l}\text { Capture } \\
\text { images }\end{array}$} & $\begin{array}{l}\text { Com } \\
\text { unic } \\
\text { env }\end{array}$ & & \\
\hline \multirow{2}{*}{$\begin{array}{c}\text { Physical form/ } \\
\text { Physical } \\
\text { Objects }\end{array}$} & & & & $\begin{array}{l}\text { Wearable } \\
\text { computer }\end{array}$ & $\begin{array}{l}\text { Walkie } \\
\text { talkie }\end{array}$ & $\begin{array}{l}\text { XDA } \\
\text { EXEC's }\end{array}$ & $\begin{array}{l}\text { Bronze } \\
\text { Software }\end{array}$ & \multicolumn{2}{|c|}{ GPS Devices } & $\begin{array}{r}\text { Hur } \\
\text { inter } \\
\text { (Key- }\end{array}$ & $\begin{array}{l}\text { man } \\
\text { faces } \\
\text { board) }\end{array}$ & \multicolumn{2}{|c|}{$\begin{array}{c}\text { Headsets } \\
\text { (head-phones } \\
\text { with mic) }\end{array}$} \\
\hline & & & & \begin{tabular}{l|l} 
Sensors & Eff
\end{tabular} & ffecters & $\begin{array}{l}\text { Comm- } \\
\text { ander }\end{array}$ & & Web came & & & aps & & \\
\hline
\end{tabular}

Figure 2 - Abstraction Decomposition Space for Sensor-Effecter activity 


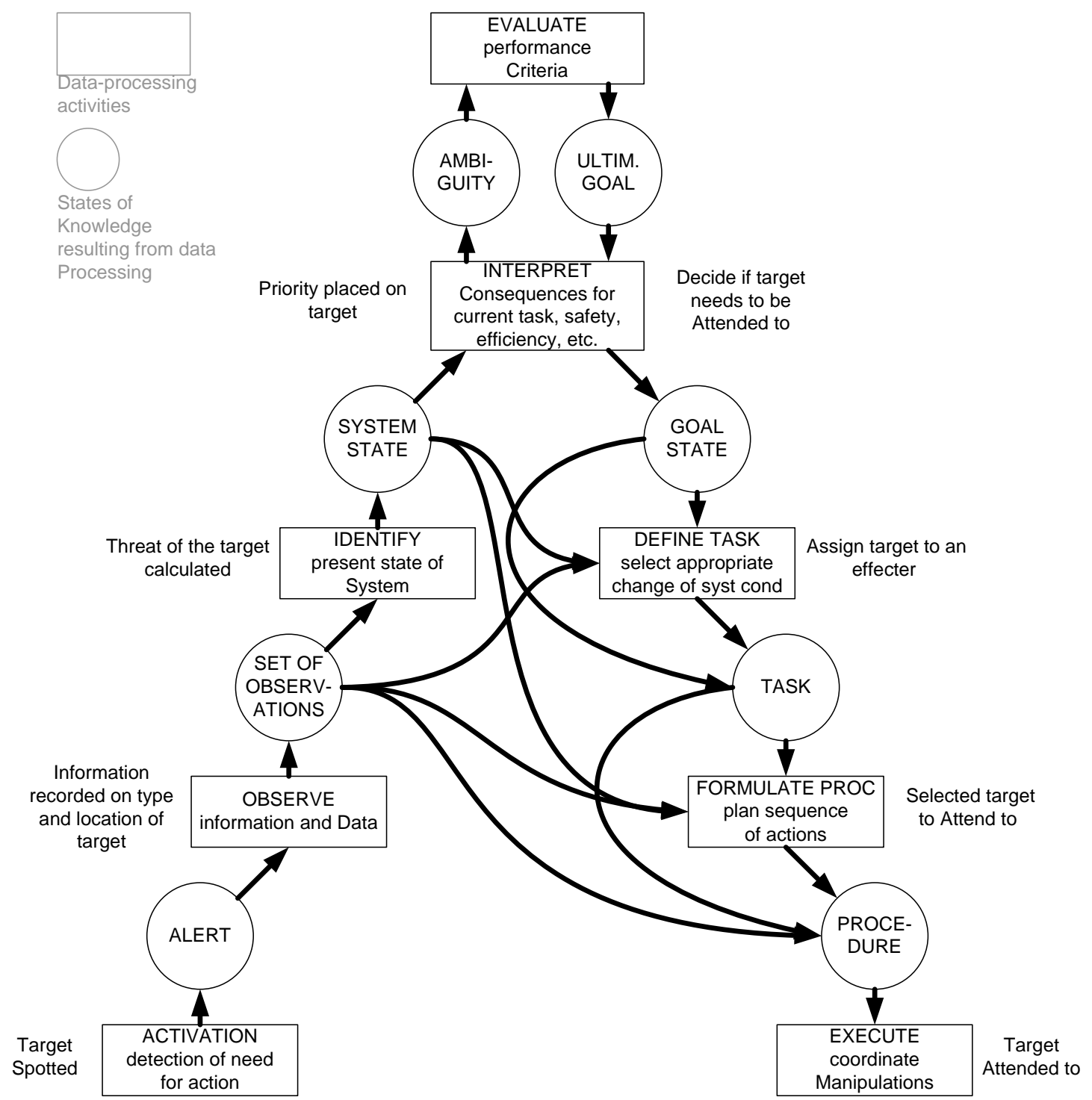

Figure 3 - Decision ladder for Sensor-Effecter activity shortened 

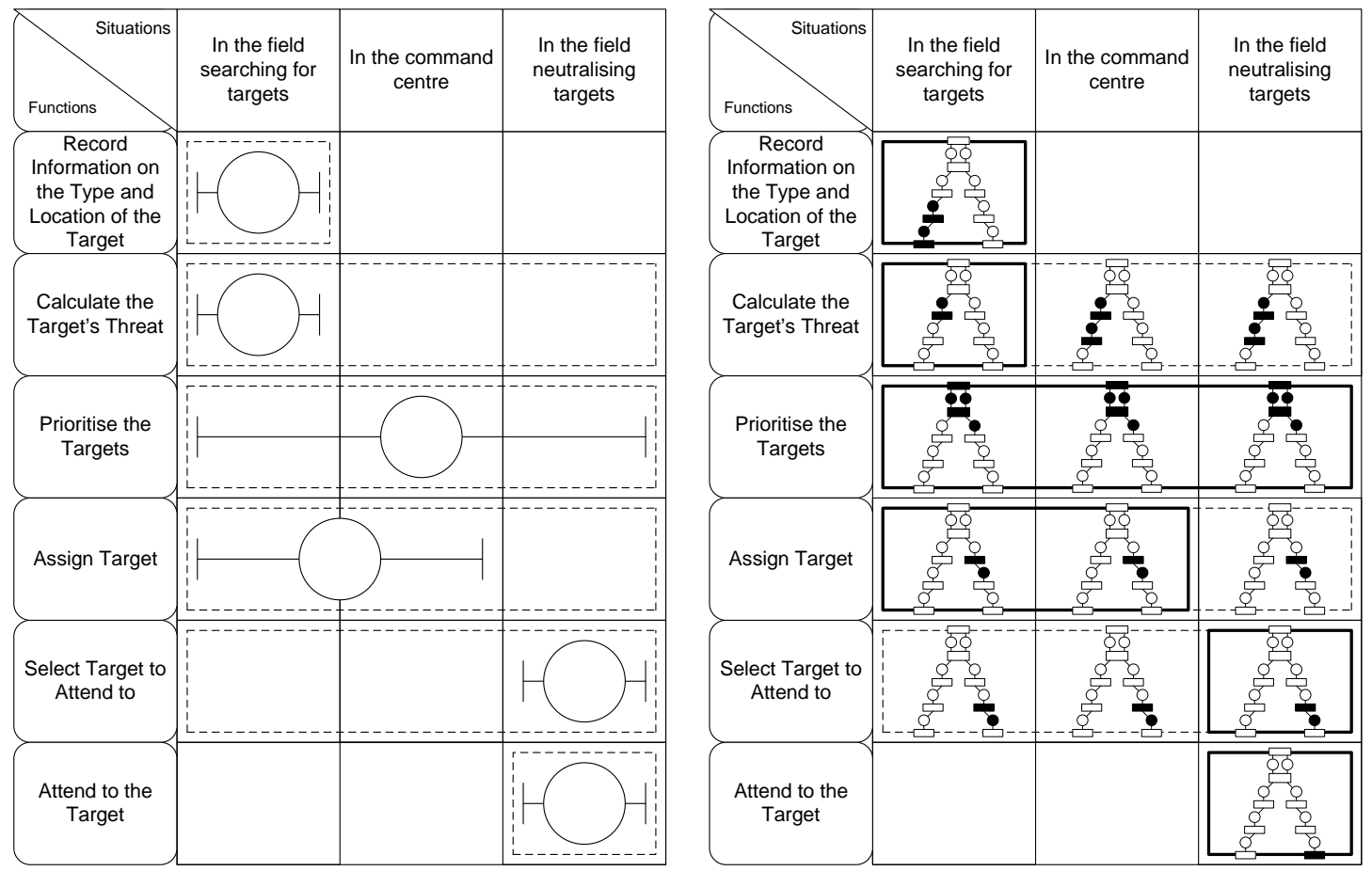

Figure 4 - Contextual activity template 
Applying CWA to the design of interfaces in complex networks

20

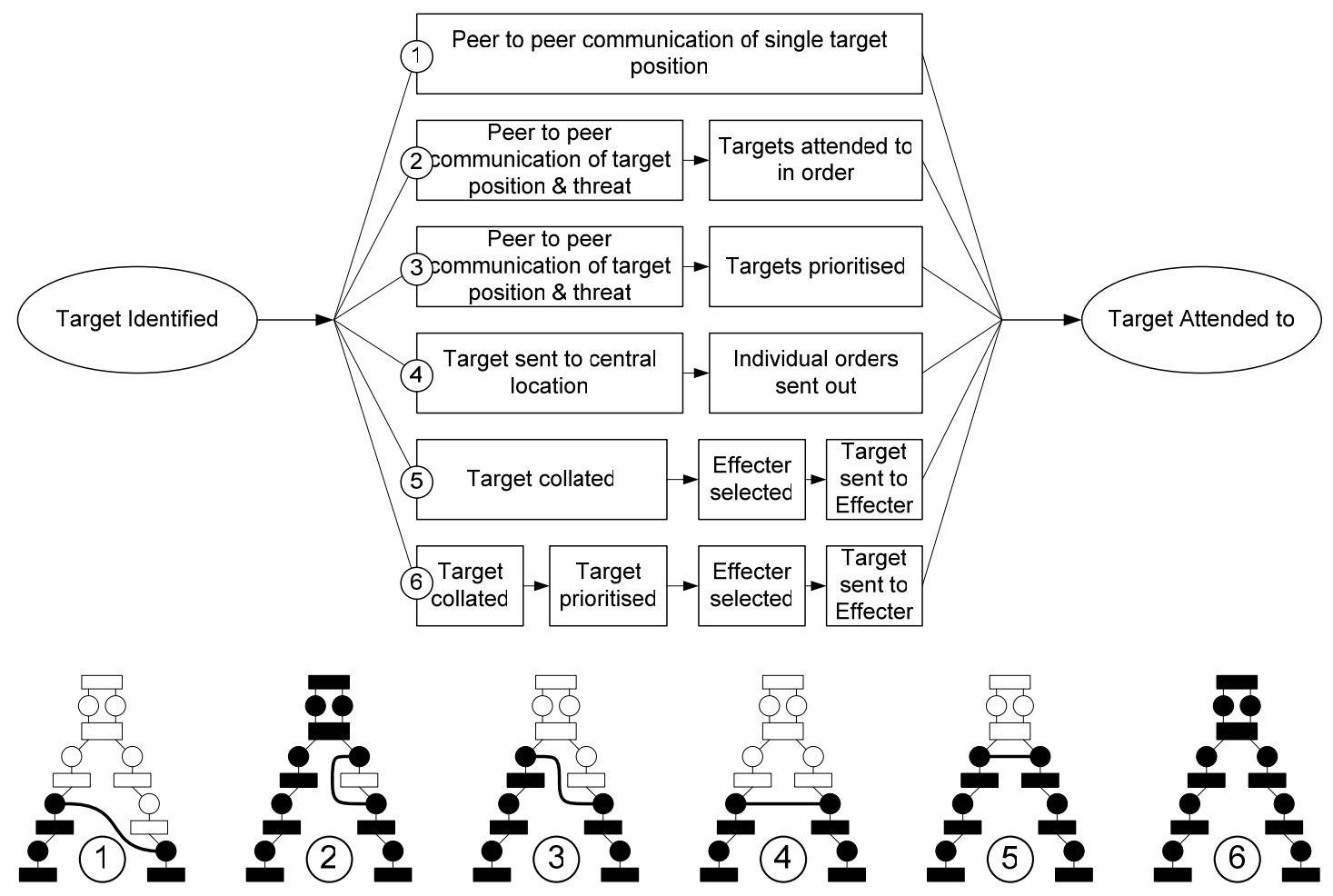

Figure 5 - Strategies analysis for Sensor-Effecter activity 


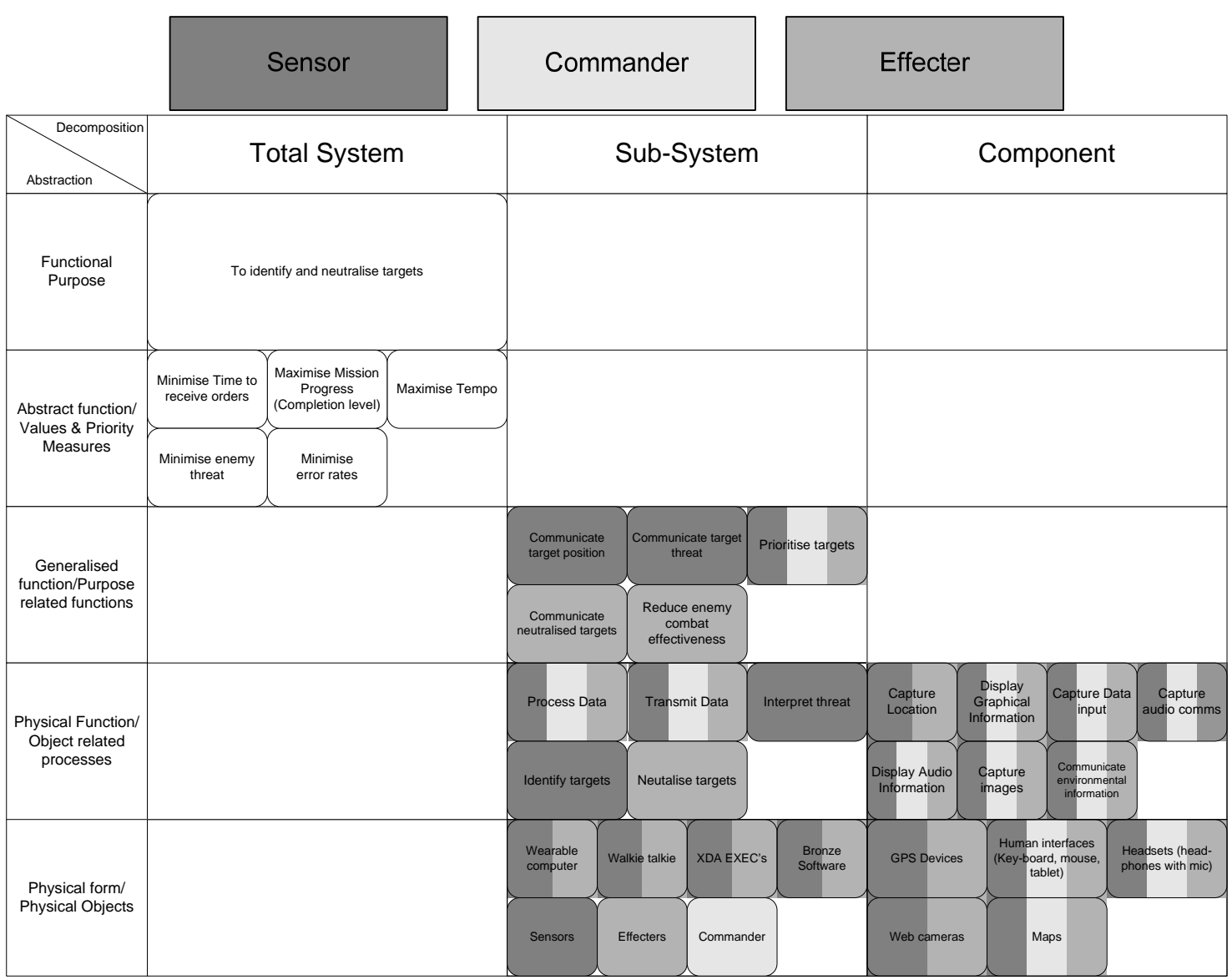

Figure 6 - ADS showing nodes used by each of the key actor groups 


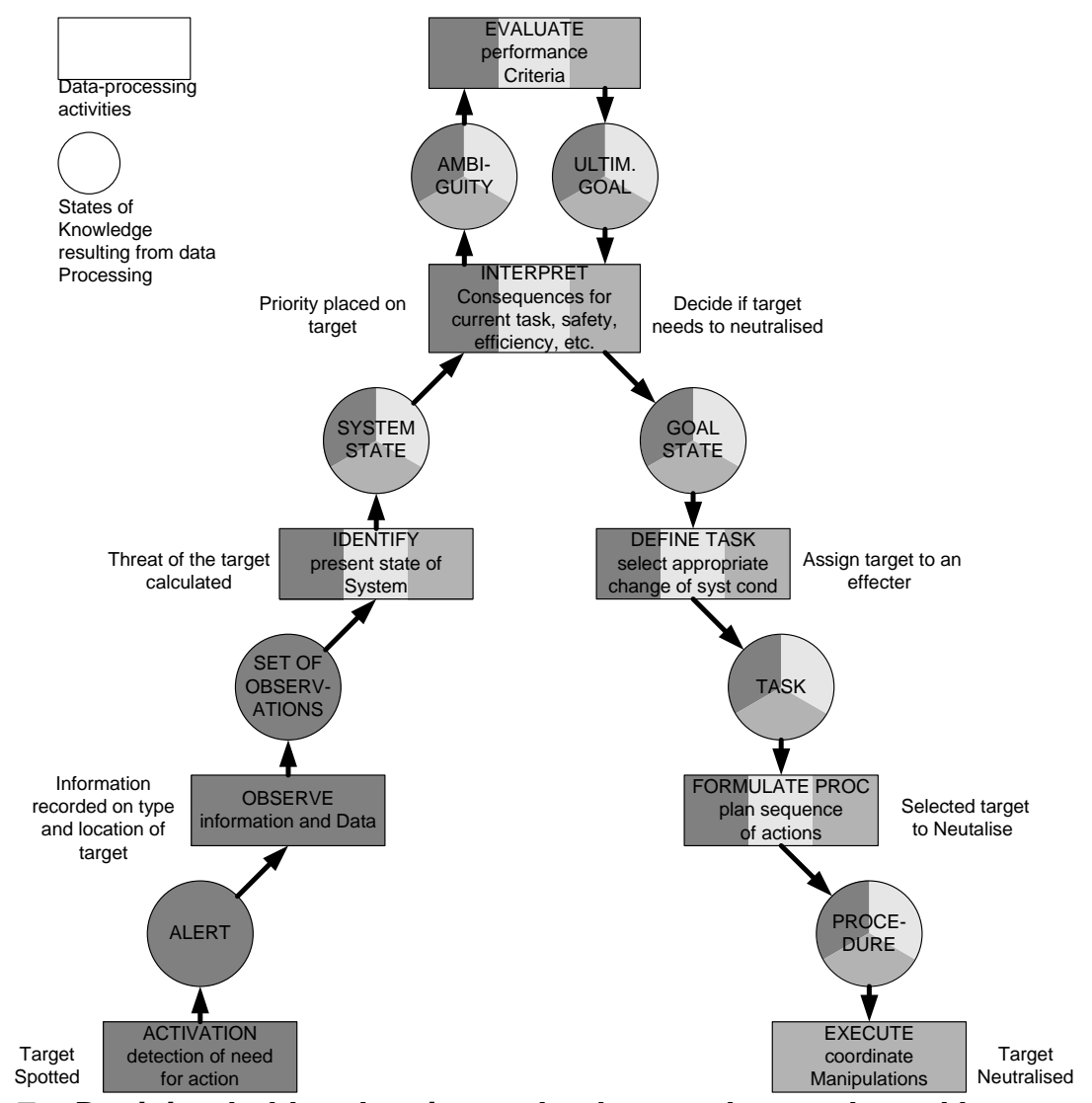

Figure 7 - Decision ladder showing tasks that can be conducted by actor types 


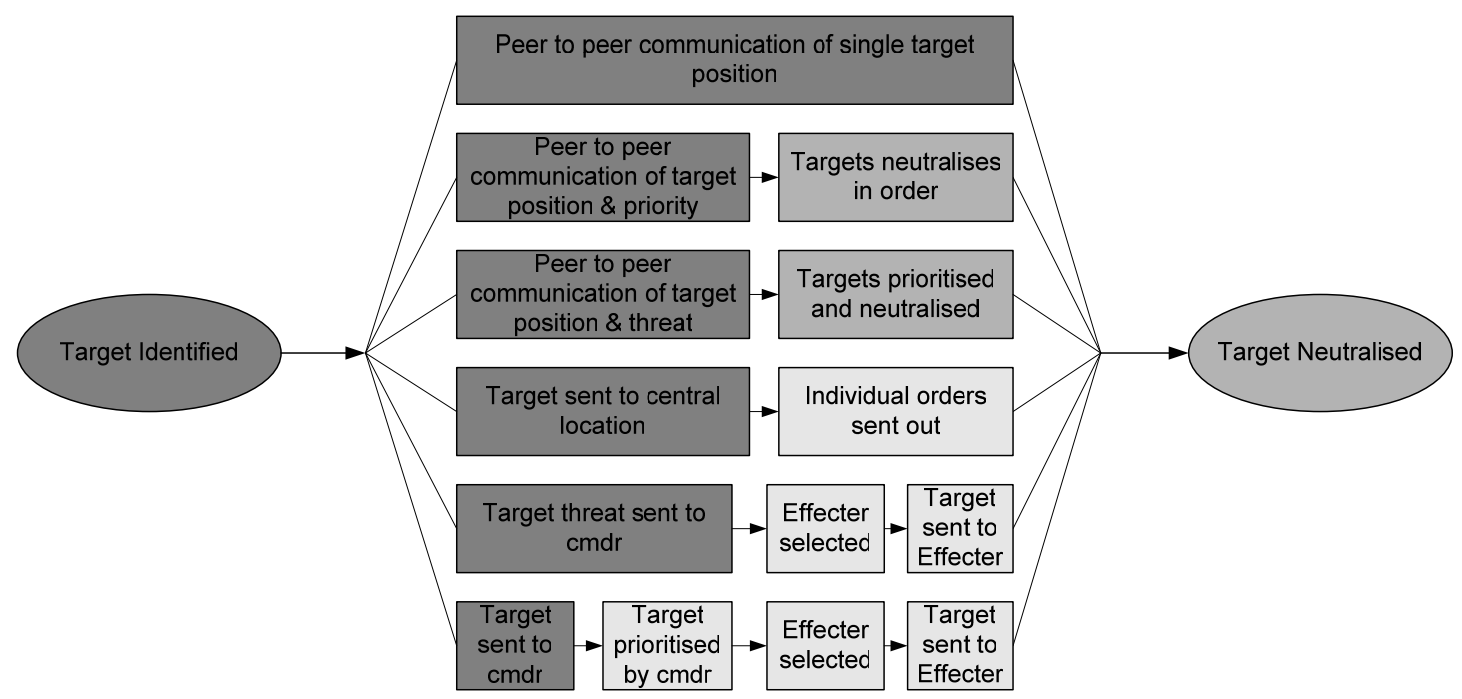

Figure 8 - Strategies analysis showing tasks that can be conducted by actor types 


\begin{tabular}{|c|c|c|c|c|c|}
\hline & \begin{tabular}{|l} 
Information \\
processing step
\end{tabular} & $\begin{array}{l}\text { Resultant state of } \\
\text { knowledge }\end{array}$ & $\begin{array}{l}\text { Skill-Based } \\
\text { Behaviour }\end{array}$ & $\begin{array}{l}\text { Rule-Based } \\
\text { Behaviour }\end{array}$ & $\begin{array}{l}\text { Knowledge-Based } \\
\text { Behaviour }\end{array}$ \\
\hline वृ & $\begin{array}{l}\text { Searching for possible } \\
\text { targets }\end{array}$ & $\begin{array}{l}\text { Whether targets are in } \\
\text { vicinity }\end{array}$ & $\begin{array}{l}\text { Monitor vicinity for } \\
\text { explicit target sightings }\end{array}$ & $\begin{array}{l}\text { Anticipate position } \\
\text { based on visual cues } \\
\text { from the environment }\end{array}$ & Infer likely positions \\
\hline & $\begin{array}{l}\text { Record information on } \\
\text { type and location of } \\
\text { target }\end{array}$ & $\begin{array}{l}\text { Understanding of } \\
\text { capabilities and } \\
\text { location }\end{array}$ & $\begin{array}{l}\text { Direct observations } \\
\text { made on target }\end{array}$ & $\begin{array}{l}\text { Experience used to } \\
\text { infer capabilities from } \\
\text { visual cues }\end{array}$ & \\
\hline 4 & $\begin{array}{l}\text { Calculate the threat of } \\
\text { the target }\end{array}$ & $\begin{array}{l}\text { Understanding of the } \\
\text { implications of the } \\
\text { targets capabilities and } \\
\text { location }\end{array}$ & $\begin{array}{l}\text { Simple conversion of } \\
\text { capabilities to threat }\end{array}$ & \begin{tabular}{|l|} 
Experience used to \\
infer threat from \\
targets capabilities and \\
location
\end{tabular} & $\begin{array}{l}\text { Target threat } \\
\text { considered against } \\
\text { overall objectives }\end{array}$ \\
\hline 9 & $\begin{array}{l}\text { Calculate the priority of } \\
\text { the target }\end{array}$ & $\begin{array}{l}\text { Understanding of the } \\
\text { relative priority of the } \\
\text { targets }\end{array}$ & $\begin{array}{l}\text { Priority based on a } \\
\text { single factor such as } \\
\text { distance threat }\end{array}$ & $\begin{array}{l}\text { Simple balance applied } \\
\text { using experience to } \\
\text { decide priority order of } \\
\text { targets }\end{array}$ & $\begin{array}{l}\text { Targets prioritised } \\
\text { considering the overall } \\
\text { objectives and } \\
\text { implications }\end{array}$ \\
\hline & $\begin{array}{l}\text { Evaluate implications } \\
\text { of neutralising target }\end{array}$ & $\begin{array}{l}\text { Understanding of } \\
\text { effects of neutralising } \\
\text { target }\end{array}$ & $\begin{array}{l}\text { Consider implications } \\
\text { based on correct } \\
\text { understanding of } \\
\text { situation }\end{array}$ & $\begin{array}{l}\text { Consider implications } \\
\text { based on previous } \\
\text { experience }\end{array}$ & $\begin{array}{l}\text { Consider implications } \\
\text { by hypothesising } \\
\text { possible implications }\end{array}$ \\
\hline & $\begin{array}{l}\text { Determine if target } \\
\text { needs to be neutralised }\end{array}$ & $\begin{array}{l}\text { Whether target is to be } \\
\text { neutralised }\end{array}$ & $\begin{array}{l}\text { Protocol used to decide } \\
\text { if target needs to be } \\
\text { neutralised }\end{array}$ & \begin{tabular}{|l|} 
Protocol used along \\
with exception \\
statements to decide if \\
target is to be \\
neutralised
\end{tabular} & $\begin{array}{l}\text { Deviations form } \\
\text { protocol considered } \\
\text { against overall } \\
\text { objective }\end{array}$ \\
\hline & $\begin{array}{l}\text { Assign Effecter to } \\
\text { target }\end{array}$ & $\begin{array}{l}\text { Effecter assigned to } \\
\text { target }\end{array}$ & $\begin{array}{l}\text { Assign target based on } \\
\text { single measure such as } \\
\text { location workload }\end{array}$ & $\begin{array}{l}\text { Use simple rules to } \\
\text { balance workload and } \\
\text { location }\end{array}$ & $\begin{array}{l}\text { Assignation based on } \\
\text { greatest effect on } \\
\text { overall system purpose }\end{array}$ \\
\hline Q & $\begin{array}{l}\text { Determine target to be } \\
\text { neutralised }\end{array}$ & Target selected & $\begin{array}{l}\text { Targets selected in } \\
\text { priority order }\end{array}$ & $\begin{array}{l}\text { Targets selected in } \\
\text { priority order unless } \\
\text { new information is } \\
\text { received }\end{array}$ & $\begin{array}{l}\text { Target selected based } \\
\text { on greatest effect on } \\
\text { overall system purpose }\end{array}$ \\
\hline
\end{tabular}

Figure 9 - SRK levels for each of the actors (representation adapted from Kilgore \& StCyr, 2006) 


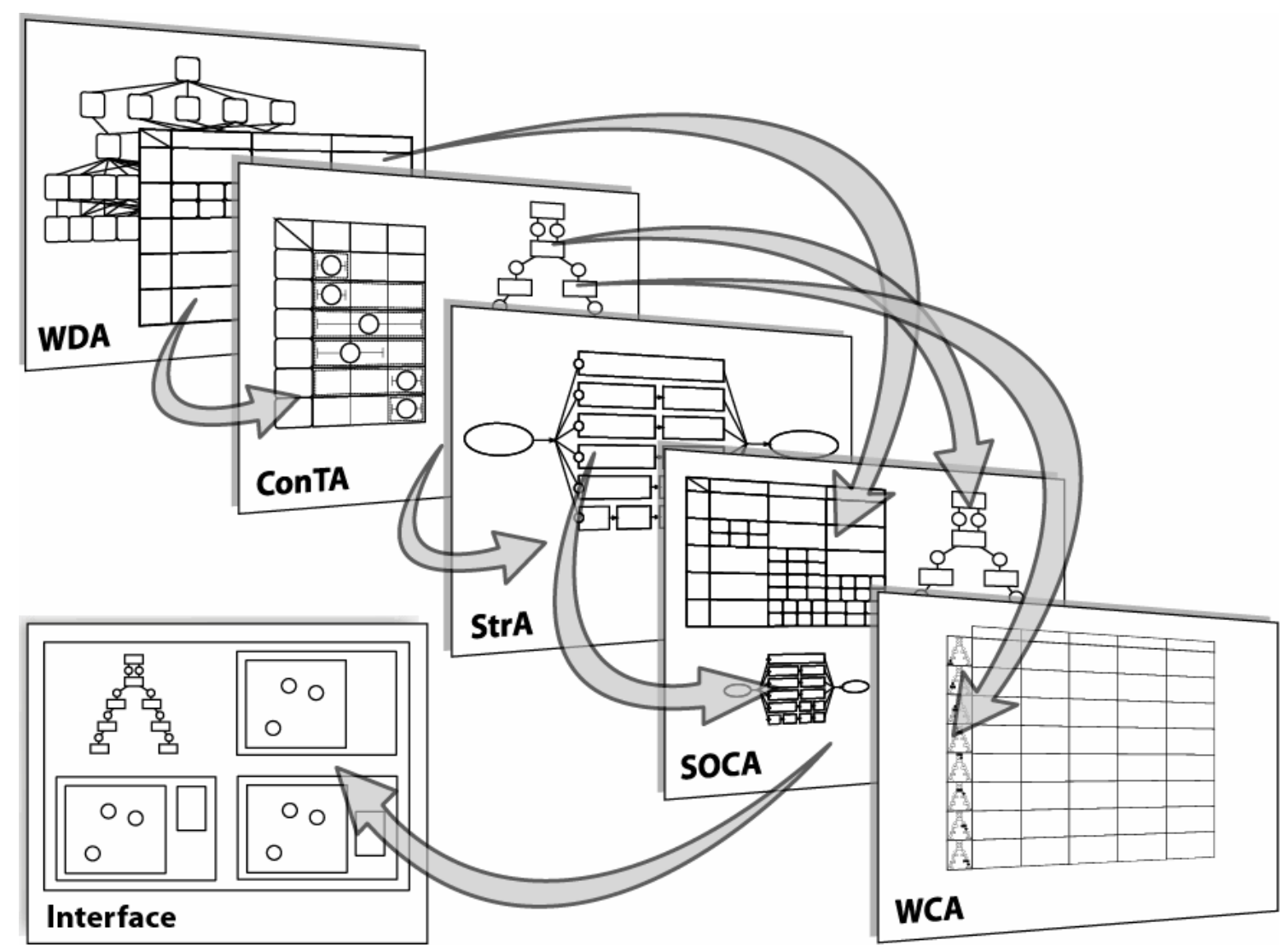

Figure 10 - Diagram showing major links between phases 

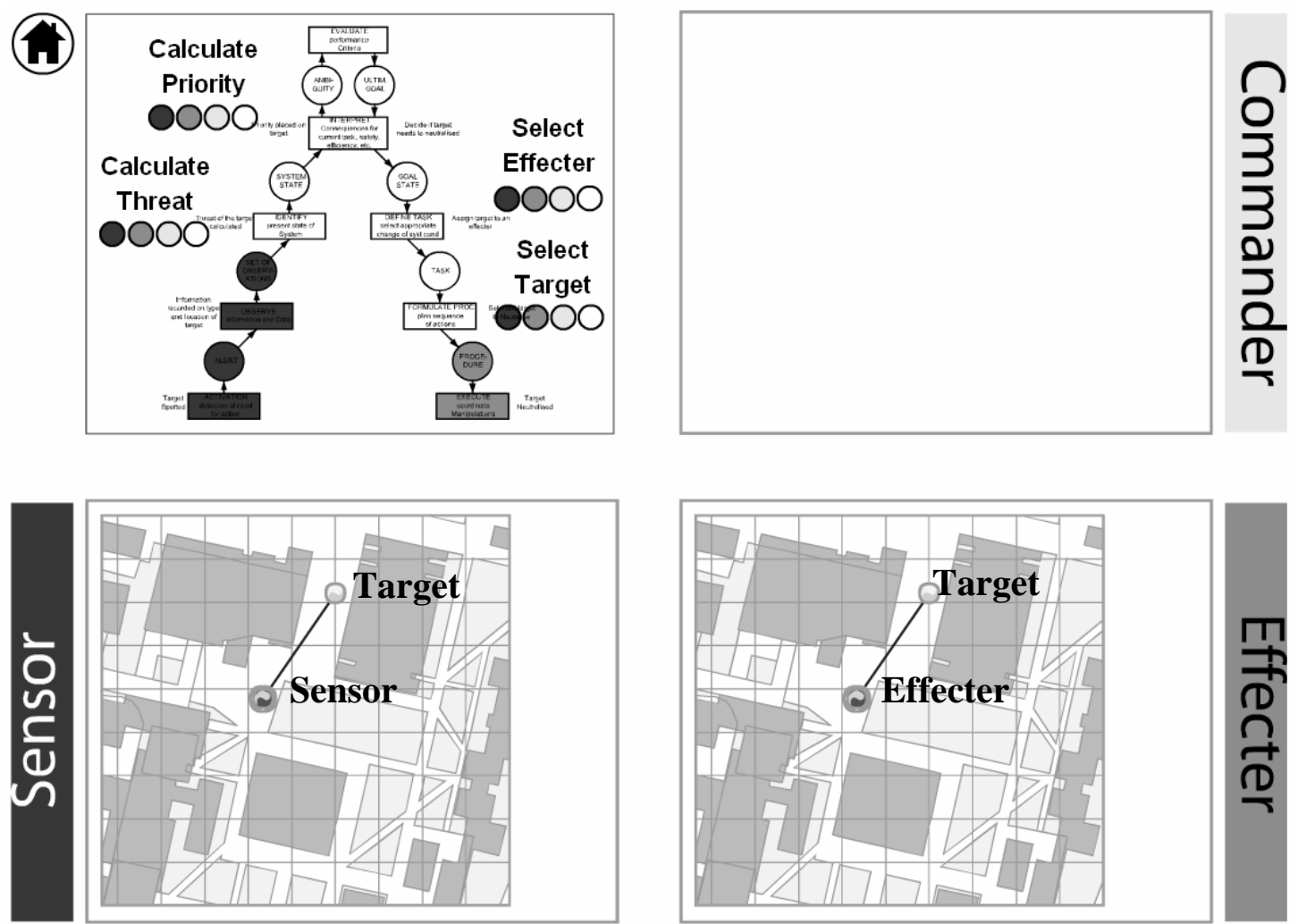

Figure 11 - Array of interfaces showing simplest configuration 

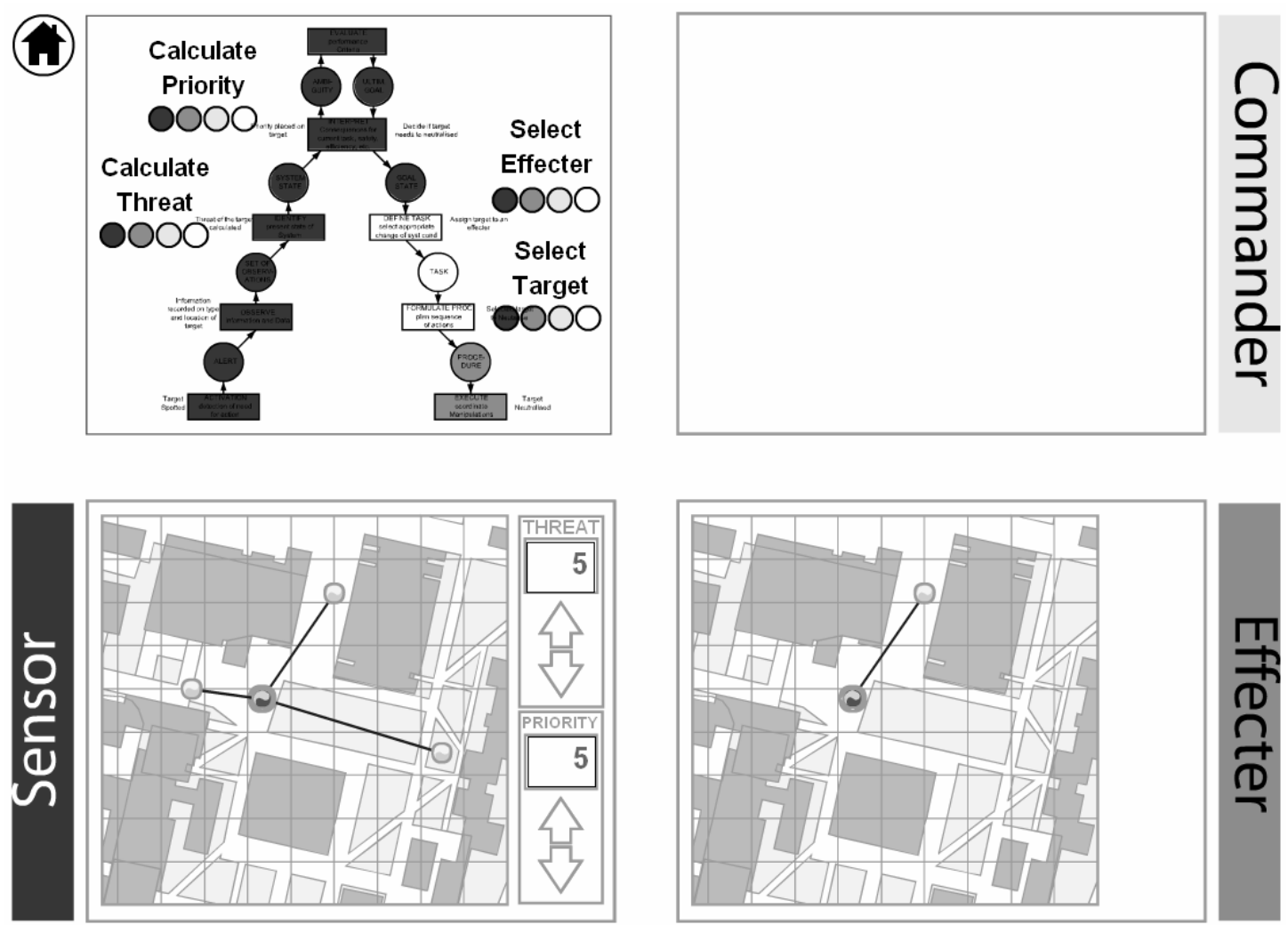

Figure 12 - Array of interfaces showing sensor assigning threat and priority. 

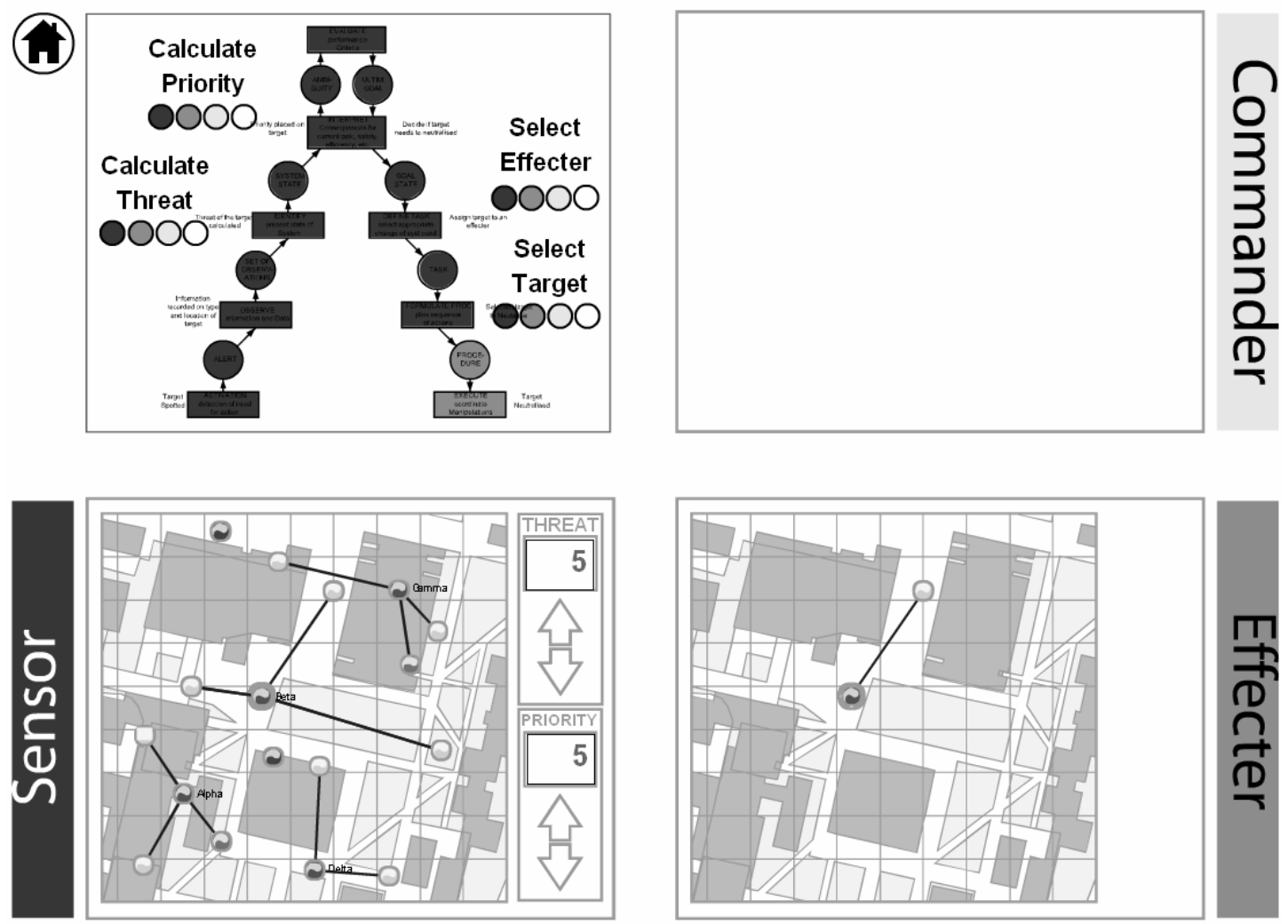

Figure 13 - Array of interfaces showing sensor assigning threat priority as well as assigning targets to effecters and selecting targets for effecters. 

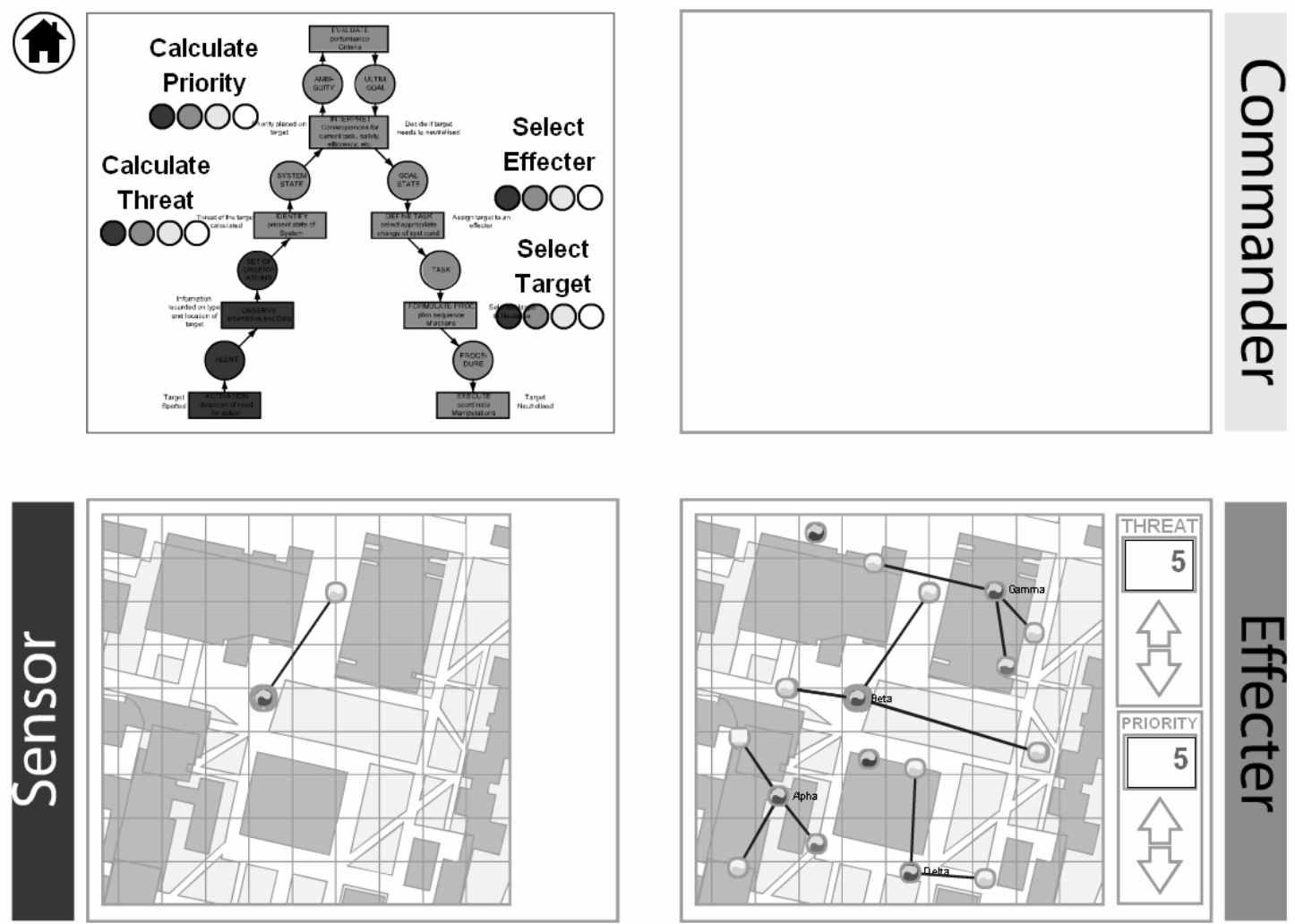

Figure 14 - Array of interfaces showing the effecter assigning threat priority as well as assigning and selecting targets. 

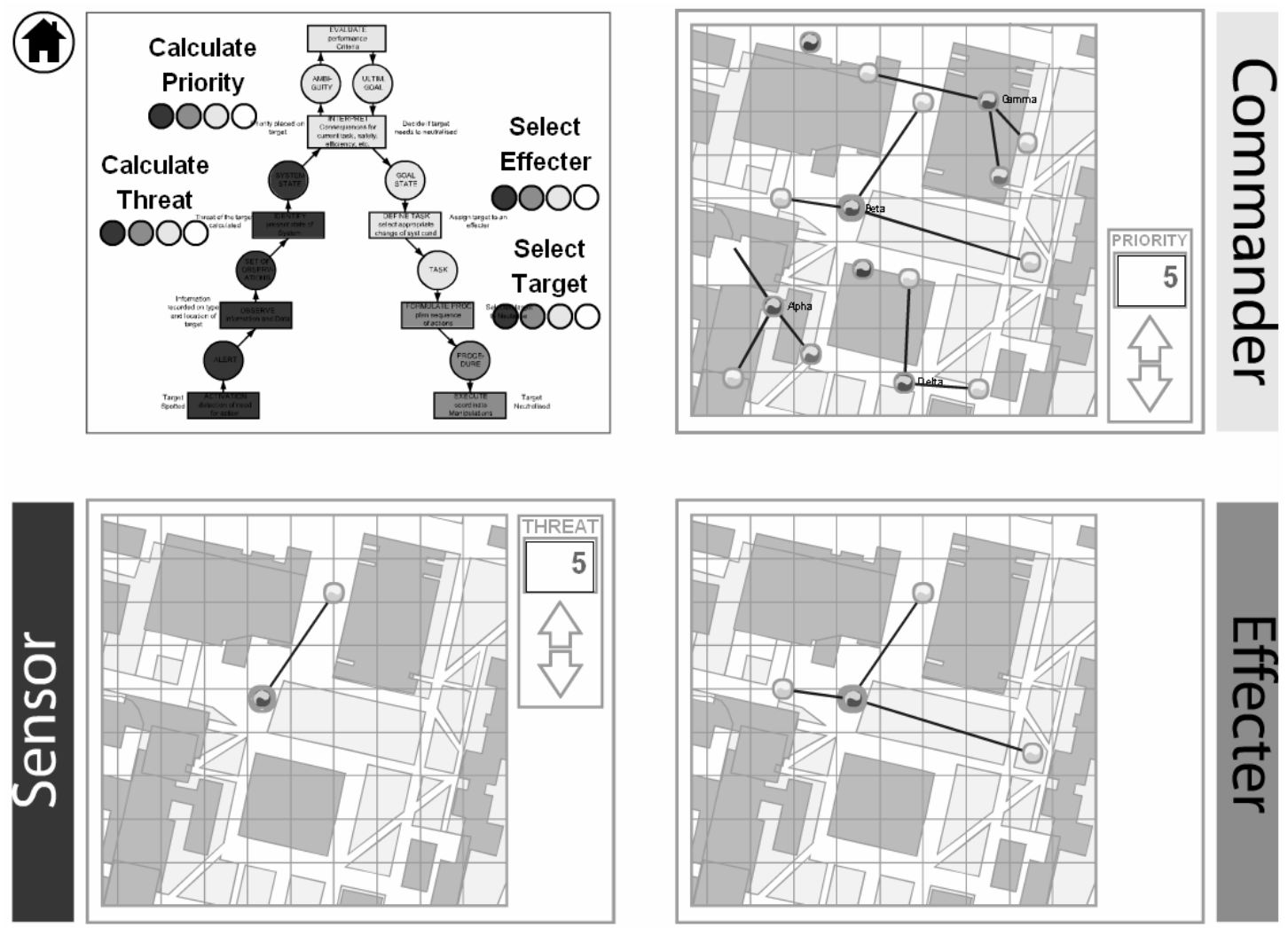

Figure 15 - Array of interfaces showing the introduction of the commander prioritising and assigning targets. 


\section{References}

AhLSTROM, U., 2005, Work domain analysis for air traffic controller weather displays. Journal of Safety Research, 36, 159-169.

BEUSCART, J.M., 2005, Napster users between community and clientele: The formation and regulation of a sociotechnical group. Sociologie du Travail, 47, S1-S16.

Bisantz, A.M., Roth, E., Brickman, B., Gosbee, L.L., Hettinger, L., \& McKinney, J., 2003, Integrating cognitive analyses in a large-scale system design process. International Journal of Human-Computer Studies, 58, 177-206.

Burns, C.M., Momtaham, K., Enomoto, Y., 2006, Supporting the strategies of cardiac nurse coordinators using cognitive work analysis, Proceedings of the Human Factors and Ergonomics Society 50th Annual meeting - 2006 pp442-446

CHERns, A., 1987, Principles of sociotechnical design revisited. Human Relations, 40(3), 153-162.

Cummings, M.L. \& GuerLain, S, 2003 The Tactical Tomahawk Conundrum: Designing Decision Support Systems for Revolutionary Domains, IEEE Systems, Man, and Cybernetics Society conference, Washington DC, October 2003.

Cummings, M.L. \& Guerlain, S, 2004 An Interactive Decision Support Tool for Realtime In-flight Replanning of Autonomous Vehicles, AIAA Unmanned Unlimited Systems, Technologies, and Operations,

Cummings, M.L., \& Guerlain, S. (in review) The Decision Ladder as an Automation Planning Tool, Cognition, Technology, and Work

DARSES, F., 2001, Providing practitioners with techniques for cognitive work analysis, Theoretical Issues in Ergonomics Science, 2:3, 268 - 277

DEKKER, A.H., 2003, Using agent-based modelling to study organisational performance and cultural differences, Proceedings of the MODSIM 2003 International Congress on Modelling and Simulation, Townsville, Queensland, 1793-1798. Available at mssanz.org.au/modsim03/Media/Articles/Vol 4 Articles/1793-1798.pdf

HAJDUKIEWICZ, J.R., 1998, Development of a structured approach for patient monitoring in the operating room. Masters Thesis. University of Toronto

HAJDUKIEWICZ, J. R. and ViCENTE, K. J. 2002, Designing for adaptation to novelty and change: The role of functional information and emergent features, Human Factors, 44, $592-610$. 
HAJDUKIEWICZ, J.R., and VICENTE, K.J., 2004, A theoretical note on the relationship between work domain analysis and task analysis, Theoretical Issues in Ergonomics Science. Vol 5 No 6 pp527-538

Higgins, P.G., 1998, Extending Cognitive Work Analysis to Manufacturing Scheduling. In P. Calder and B. Thomas (Eds.) Proceedings 1998 Australian Computer Human Interaction Conference, OzCHI'98, November 30-December 4, Adelaide, IEEE, pp. 236-243.

JAMIESON, G.A., \& ViCENTE, K.J., 2001, Ecological interface design for petrochemical applications: Supporting operator adaptation, continuous learning, \& distributed, collaborative work. Computers and Chemical Engineering, 25, 1055-1074

Jenkins, D. P., Stanton, N. A., Salmon, P. M, Walker, G. H., \& Young, M. S., in press, Cognitive Work Analysis of a Sensor to Effecter System: Implications for Network Structures. Human Factors and Ergonomics Society Europe Chapter Meeting 2006.

JSP 777, 2004, Joint Service Publication 777 - Network Enabled Capability, http://www.mod.uk/DefenceInternet/AboutDefence/CorporatePublications/Scienceand TechnologyPublications/NEC/

KILGORE, R., \& ST-CYR, O., 2006, SRK Inventory: A tool for structuring and capturing a worker companies analysis. Proceedings of the Human Factors and Ergonomics Society 50th Annual Meeting 2006 pp. 506-509

Lintern, G., Cone, S., Schenaker, M., Ehlert, J., \& Hughes, T., 2004, Asymmetric Adversary Analysis for Intelligent Preparation of the Battlespace (A3-IPB) United States Air Force Research Department Report

Miller, A., 2004, A work domain analysis framework for modelling intensive care unit patients. Cognition, Technology and Work. Vol. 6, No. 4. (November 2004), pp. 207-222.

NAIKAR, N., 2006 An Examination of the Key Concepts of the Five Phases of Cognitive Work Analysis with Examples from a Familiar System. Proceedings of the Human Factors and Ergonomics Society 50th Annual Meeting 2006 pp. 447-451

NAiKar, N., Moylan, A. \& PeArCe, B., 2006, Analysing activity in complex systems with cognitive work analysis: Concepts, guidelines, and case study for control task analysis. Theoretical Issues in Ergonomics Science. Vol 7 No 4 pp371-394

NAIKAR, N, Hopcroft, R, \& MoYlan, A., 2005, Work Domain Analysis: Theoretical Concepts and Methodology. DSTO-TR-1665 System Sciences Laboratory: Edinburgh, Australia. 
NAikar, N., PeArce, B., Drumm, D., \& SAnderson, P. M., 2003, Technique for designing teams for first-of-a-kind complex systems with cognitive work analysis: Case study. Human Factors, 45(2), 202-217.

NAIKAR, N. \& SANDERSON, P.M., 1999, Work domain analysis for training-system definition. International Journal of Aviation Psychology, 9, 271-290.

NAIKAR, N., \& SANDERSON, P.M., 2001, Evaluating design proposals for complex systems with work domain analysis. Human Factors, 43, 529-542.

NAIKAR, N., \& SAUNDERS, A., 2003, Crossing the boundaries of safe operation: A technical training approach to error management. Cognition Technology and Work, 5, 171-180.

OLSSON, G., \& LEE, P.L., 1994, Effective interfaces for process operators. The Journal of Process Control, 4, 99-107.

RASMUSSEN, J., 1986. Information processing and human-machine interaction: An approach to cognitive engineering. New York: Elsevier Science Publishers.

Rasmussen, J., Pejtersen, A., \& Goodstein, L., 1994, Cognitive Systems Engineering. New York: Wiley.

Salmon, P.M., Stanton, N. A., Regan, M., Lenne, M., \& Young, K., In Press, Work domain analysis and road transport: Implications for vehicle design. International Journal of Vehicle Design.

SANDERSON, P. M. (2003). Cognitive Work Analysis across the system life-cycle: Achievements, challenges, and prospects in aviation. In P. Pfister \& G. Edkins (Eds.). Aviation Resource Management (Vol 3). Aldershot, UK Ashgate.

ViCENTE, K. J. 2002, Ecological interface design: Progress and challenges, Human Factors, 44, $62-78$.

VICENTE, K. J., 1999, Cognitive work analysis: Toward safe, productive, and healthy computer-based work. Mahwah, NJ: Lawrence Erlbaum Associates

\section{Biographies}

Daniel Jenkins is a Research Fellow at Brunel University, Human Factors Integration Defence Technology Centre. Dan was awarded a MEng in Mechanical Engineering and Design in 2004 by Brunel University 
Prof Neville Stanton is based at Brunel University, Human Factors Integration Defence Technology Centre. Neville was awarded a PhD in Human Factors in 1993 by Aston University

Dr Guy Walker is a Research Fellow at Brunel University, Human Factors Integration Defence Technology Centre. Guy gained his PhD in user-centred design in 2002 from Brunel University

Paul Salmon is a Research Fellow at Brunel University, Human Factors Integration Defence Technology Centre. Paul was awarded an MSc in Applied Ergonomics, 2001, by the University of Sunderland, Institute for Automotive Advanced Manufacturing Practice (AMAP), UK

Dr Mark Young is a Research Lecturer at Brunel University, Human Factors Integration Defence Technology Centre. Mark was awarded a PhD in Human Factors in 2000 by the University of Southampton 